\title{
Bach: la rama española
}

\section{Bach: the Branch of the Family in Spain}

\author{
Luca Purchiaroni \\ Istituto Comprensivo Paolo III, Canino \\ lucapurchiaroni@yahoo.it \\ ORCID iD: https://orcid.org/0000-0001-6937-8333
}

\section{RESUMEN}

¿De dónde viene y a cuándo se remonta el apellido Bach en España? ¿Puede que algún miembro de la familia del gran Johann Sebastian, posiblemente músico, se hubiera afincado de alguna manera en la península ibérica antaño? La presencia de un organista español con este patronímico inequívocamente alemán en la Capilla Musical del convento madrileño de las Descalzas Reales en el siglo XVIII, más el hecho de que en Cataluña, y en particular en la provincia de Gerona, sobrevivan hoy en día muchos Bach, han sido alicientes suficientes para llevar a cabo esta investigación genealógica, que llega nada menos que a la época de los últimos Templarios.

Palabras clave: Bach, Gerona, capilla musical, descalzas reales, templarios.

\begin{abstract}
Where does the surname Bach come from in Spain, and how old is it? Is it possible that a member of Johann Sebastian's family, probably a musician, had settled somewhere in the Iberian Peninsula a long time ago? The presence of a Spanish organist named José Bach, active in Madrid in the $18^{\text {th }}$ century, in addition to the current high concentration of this patronymic in the Catalan area, have inspired me to run this genealogical research, which goes way back to the age of the last Knights Templar.
\end{abstract}

Key Words: Bach, Gerona, genealogy, Descalzas Reales, Knights Templar. 
Purchiaroni, L. (2021). Bach: la rama española. Cuadernos de Investigación Musical, (13), pp. 106-114.

\section{INTRODUCCIÓN}

Sabemos que al famoso Antonio de Cabezón (1510-1566) se le llama "el Bach español”, por el genio compositivo, la sabiduría contrapuntística. Pero ¿cuántos de nosotros saben que existió un Bach español de verdad, de carne y hueso, con el nombre de Joseph (o José), ejerciendo en Madrid como organista en el siglo XVIII?

Esta noticia, más el hecho de que en Cataluña, y en particular en la zona de Gerona, el apellido Bach siga estando muy extendido, me empujó a investigar sobre la posibilidad de que pudiera haber algún enlace con la familia de Johann Sebastian; sobre todo considerando que su apellido era sinónimo de músico. He llegado a pensar que algún antepasado del genio alemán podría haber llegado a España siguiendo a alguno de los Habsburgo, de ahí que arrancó mi búsqueda.

La genealogía de los Bach alemanes sigue siendo un tema muy estudiado, un terreno resbaladizo al punto que las nuevas aportaciones dejan irremediablemente obsoletos los libros más acreditados ${ }^{1}$. Sabemos que el mismo Kapellmeister estaba muy interesado en conocer a fondo sus orígenes y que al cumplir los cincuenta años empezó a reconstruir, con mucha paciencia, aquel árbol genealógico ${ }^{2}$ que le sirvió luego después a Forkel para redactar su primera biografía. Él había llegado a la quinta generación hasta dar con el famoso Veit, un molinero aficionado a la cítara, muerto antes de 1578 en Wechmar (Turingia), después de escapar de Bohemia (hoy Hungría) por su fe luterana. Desde aquella generación en adelante, todos los Bach se dedicaron a la música.

Los Bach no solían desplazarse muy lejos uno del otro, preferían vivir siempre cerca de algún pariente, para ayudarse mutuamente frente a las dificultades. De hecho, eran conocidos como un clan, una tribu, un gremio muy potente que quería tener la exclusiva sobre la música que se tocaba en su área de residencia.

En cuanto a los Bach antecesores de Vitus, o Veit, hasta ahora solo se han encontrado documentos acerca de un tal Hans Bach que datan de 1509. Sin embargo, este patronímico existía ya desde hacía mucho, en Alemania. Un ejemplo de ello - quizás el más remoto de todos los que se han detectados hasta ahora - lo encontramos curiosamente en Italia, cuando en 1354 la Señoría de Padua quiso mandar una guarnición de soldados alemanes a Verona, en socorro de Can Grande de la Escala que estaba defendiéndose del hermano usurpador. Entre ellos figuraba el caballero Quirico de Bach (Biancolini, 1766, pp. 176-177).

\footnotetext{
${ }^{1}$ Cfr. Brück 2008; Frickel, 1994; Kock 1995; Klaus-Rüdiger, 2013.

${ }^{2}$ Ursprung der musicalish-Bachischen Familie es el título original.
} 


\section{Luca Purchiaroni}

Siempre se ha hablado de los Bach alemanes, de los que viajaron y se afincaron en Inglaterra, en Francia y hasta en Estados Unidos, pero nunca de su posible rama española. Y puede, incluso, que sea ésta la más antigua, o una de las más antiguas de todas. De hecho, en una tesis doctoral procedente de la Facultad de Filosofía y Letras de la Scuola Normale de Pisa se describe el claustro de un monasterio medieval situado en Arles-sur-Tech (Occitania, Francia), tallado en un precioso mármol de los Pirineos y en la piedra calcárea de Gerona, «realizado bajo los auspicios del abad Raimond des Bach» (Español, 2003, p. 215; 2009, pp. 963-1001).

Vamos a ver, entonces, quién era en realidad este abad y todos los demás Bach españoles más destacados que hemos encontrado a lo largo de la historia, para ver si existe una conexión con la rama alemana.

\section{RAYMOND (RAIMOND) DEZ (DES) BACH (SIGLO XIII)}

Francesca Español (2009, p. 965), la autora de la tesis antes citada, considera el año 1261 como fecha de nacimiento de este abad y 1303 como año de su muerte. Si prestamos fe a estos datos, el personaje en cuestión podría coincidir con un templario, nada menos que un "preceptor", es decir, el que se encargaba de la iniciación de los adeptos.

Las crónicas de aquel tiempo narran de un juicio contra estos últimos caballeros de la gloriosa Orden del Templo de Jerusalén, arrestados en 1307 por voluntad del rey de Francia Felipe IV ("el Hermoso") y recluidos en la fortaleza del Masdéu (Mas-Deu = Mansio Dei), en la ciudad de Elne (Occitania, cerca de Perpiñán). Tres años más tarde, cuando finalmente empezó el interrogatorio a cargo de Raymond Costa obispo de Elne, uno de ellos, y precisamente fray Bartomeu de Torre, contó la manera en que fue «recibido en la casa del Masdéu por fray Raymond dez Bach, por entonces preceptor, en la Nochebuena, hace veintinueve años [1281, N.d.A.]» para prestar juramento a la Orden (Uda, 2008, pp. 103-110). Este relato está considerado, entre otras cosas, como la más detallada aclaración del sistema secreto de afiliación practicado entre los Templarios.

En un acta notarial del siglo XIX, en cambio, encontramos trazas de un traslado de los restos mortales de un tal Raymundo dez Bach, juntos con otros cuerpos, desde Besalú a Barcelona. Era el año 1891, cuando la iglesia barcelonesa de Santa María de Ripoll acogió «los restos de Ramón Berenguer III [conde de Barcelona, llamado el Grande, N.d.A.] y otros ilustres personajes», entre los cuales figuraba este Raymundo dez Bach, «varón de nobilísima familia, contemporáneo y amigo de San Bernardo Calbó [1180-1243, N.d.A], que se distinguió entre los benedictinos por sus relevantes dotes y virtudes, siendo proclamado abad en el año 1217; y Beltrán dez Bach, deudo del anterior y Prior que fue del histórico y venerado Monasterio de Montserratı ${ }^{3}$.

\footnotetext{
${ }^{3}$ Ripoll, panteón de los Condes de Barcelona y de Besalú, acta de la Audiencia de Barcelona (353-), establecimiento gráfico de Jaime Jepús, 1893 (Biblioteca virtual Miguel de Cervantes).
} 


\section{FRANCISC BACH (SIGLO XIV)}

Otro Bach que hemos encontrado en esta búsqueda, que por antigüedad va después del abad Raymond, es un clérigo de Peralada (Gerona): Francisc Bach (Bac, Bacò, ¿Baçon?), ordenado subdiácono en 1341. Llegó a ser nombrado Prior provincial en 1366, después de haber estado dos veces en París para estudiar, la primera en 1357 y la segunda en 1362 (Webster, 1999, cap. IV, p. 94). Se hablaba de él como uno de los más distinguidos carmelitas (ibid., p. 89) y vivió, por lo menos, hasta 1370 (ibid.., p. 81).

\section{PERE BACH (SIGLO XIV)}

Este otro Bach consiguió el bachillerato en Leyes y fue juez en la Vall d'Aran. El 12 de junio de 1359 se le dio permiso para estudiar tres años en un "Estudi general" . En otra fuente se ha encontrado un "Pere des Bach o dez Bach, senyor de Rocabruna" y, por las fechas y el poder que le otorgaba su oficio, podría coincidir con el mismo (Dalmau, 1971, vol. 3, p. 29).

\section{Capitán N. Dez BaCH}

En 1463, los capitanes “N. Dez Bach y Juan Callar”, que estaban afincados en Gerona, habían levantado dos compañías mallorquinas para combatir junto al rey de Aragón contra los catalanes que por entonces estaban apoyados por los franceses (Dameto, 1841, p. 437). Hay una carta, escrita por el rey Don Juan II de Aragón al obispo de Gerona, que lo cita 5 .

\section{SIGLOS XVI-XVII}

Buscando en los registros de bautizados por la parroquia de Santa María de Castelló de Ampurias (Gerona) entre 1502 y 1940, aparecen nombres como Marti Johan Bach (29/08/1533) y Johan Miguel Bach (06/10/1534). Los dos parecen ser hijos del mismo padre: Johan Bach, un nombre, esta vez, inequívocamente extranjero, que demuestra una voluntad de perpetuar los antiguos orígenes teutónicos. Entre 1593 y 1594 nacen Pere y Miguel Des Bach en Sant Feliu, cuyo padre es otro Pere Des Bach, como el juez encontrado en el siglo XIV.

Entre los matrimonios, en cambio, ha aparecido un tal Domingo Bach que, el 19 de noviembre de 1591, se casó con Anna de Genover. En los registros de difuntos, en cambio, aparece por ejemplo una tal Maria Bach (1620 - 1680, Ciurana, Gerona). Así como en 1661 aparece un tal Joan Comas I Bach en Sant Feliu de Pallerols, junto a muchos hermanos y parientes, cuya madre es Margarida Bach.

\footnotetext{
${ }^{4}$ Documents per a la história de la cultura catalana medieval, vol. 2 (Reg. 968, f. 9.), Institut d'Estudis Catalans, 2000, p. 100.

${ }_{5}$ Reducció de Castelló de Ampurias. Cartas del rey Don Juan al bisbe de Girona, qui ab sos homens de armas ix cavalcant en persecució dels francesos è italians fugitius. Ab lo Bisbe anaren son Nebot Bernat baró de Senesterra y son germá Francisco Margarit veguer de Girona. Táctica de las capitulacions de Castelló mantigudas secretas (Fol. 178a) (Alfonsello, 1873, p. 35, nota 6).
} 


\section{LUCA PURCHIARONI}

En fin, durante todo el siglo XVIII, los Bach siguen afincados sobre todo en las ciudades de Olot, Amer y San Gregori ${ }^{6}$.

\section{JoSEPH (JOSÉ) BACH}

He aquí el único, entre todos los Bach nacidos en España, que se sepa que ejerció como músico, y más exactamente organista. Su vida corre casi paralela a la del renombrado Johann Sebastian, nacido a más de mil kilómetros de distancia.

Este músico gerundense, hoy en día lamentablemente inédito y prácticamente desconocido ${ }^{7}$, nació en Olot $^{8}$ (Cataluña), a principios de 1700, de Don Joseph Bach y Doña Jerónima Bacha Juanetas (Subirá, 1958, p. 217).

Después de recibir una probable primera formación en la Capilla Musical del Monasterio de Montserrat, en 1740 lo encontramos en Madrid, viviendo en las "casas de Memoria" (Subirá, 1958, p. 217) y trabajando en el Convento de las Descalzas Reales ${ }^{10}$ como tesorero y organizador de fiestas. Su mujer, la viuda cordobesa Catalina Pérez de la Torre, murió al cabo de tres años (Barrio Moya, 1998, p. 353) y, el 21 de enero de 1744, Joseph se casó en segundas nupcias con Doña Jerónima Marcos, de Valdeavero. De ese matrimonio nació el hijo heredero José Benito (21 de marzo de 1754$)^{11}$ que, como veremos más adelante, parece seguir las huellas del padre.

En algún momento impreciso, José Bach pasó a ser "organista primero de la Capilla de las Descalzas Reales" (Subirá, 1958, p. 217) ${ }^{12}$, de los cuatro que había de plantilla por entonces. Lo que sí es cierto es que este cargo no le debió de durar mucho, puesto que en 1751 la plaza resultaba ocupada por José de Nebra ${ }^{13}$. Tampoco conocemos las razones de su alejamiento, pues el título podía durar indefinidamente hasta que las condiciones de salud lo

\footnotetext{
${ }^{6}$ Datos encontrados en la página web de la Iglesia de los Santos de los últimos días, donde se pueden consultar libremente todos los libros de bautizo, matrimonio y muerte desde 1502 hasta 1940.

${ }^{7}$ Hace ya más de veinte años que Barrio Moya lamentaba la falta de investigaciones sobre el importante fondo musical de esta capilla musical, documentación que actualmente se encuentra en la Real Biblioteca de Palacio. Sin embargo, búsquedas más recientes, como la tesis doctoral de Judith Ortega Rodríguez, no han aportado novedades sobre este compositor en particular, no habiéndose encontrado todavía ninguna partitura que se le pueda atribuir.

${ }^{8}$ La misma ciudad donde nació, en 1729, Antonio Soler, supuesto alumno de Domenico Scarlatti y organista en el Escorial.

${ }^{9}$ Edificios construidos para la dependencia de la corte, ubicados en la antigua Calle de la Sartén, a poca distancia del Palacio Real y del convento de las Descalzas Reales.

${ }_{10}$ Nombre con el que se llamaba el monasterio de franciscanas clarisas de Nuestra Señora de la Consolación, fundado en 1559 por la princesa Doña Juana de Austria, hija de Carlos V (hermana de Felipe II, viuda del príncipe Juan Manuel de Portugal, madre del futuro rey portugués don Sebastián). El monasterio se encuentra situado en pleno centro de Madrid, en la actual plaza de las Descalzas, zona cercana a la Puerta del Sol, plaza de Celenque y calle de Preciados. Es un edificio clasicista del siglo XVI que alberga en su interior importantes obras de arte. Parte del monasterio está en la actualidad dedicado a museo que se puede visitar [página web del monasterio de las descalzas].

11 Rif. “37 Baut. Fol. 202”. Otras fuentes nos informan que la pareja tuvo dos hijos más, que evidentemente no sobrevivieron: José, nacido el 21 de enero de 1749 (rif. “35 Baut. Fol. 480”) y Mariana, nacida el 25 de julio de 1757 (rif. “38 Baut. Fol. 165”) (Fernández García, 2004, p. 91). José Benito sería el mediano.

12 Barrio Moya (1998, p. 353) hipotetiza una fecha entorno al 1750, pero no hay documentos que lo prueben.

${ }^{13}$ En 1751 el rey ascendía a vicemaestro de capilla a José de Nebra, "por concurrir en él las cualidades que se requiere para que la sirva puntualmente con la plaza de organista principal que actualmente obtiene” (Ortega Rodríguez, 2010, p. 57).
} 
permitieran o, como en el caso de José de Nebra, hasta el fallecimiento, que en el caso de José Bach se produjo el 23 de enero de 1771.

Respetando sus últimas voluntades, recogidas en el testamento escrito junto a su mujer el 2 de octubre de 1770, el músico fue sepultado "de secreto con lizenzia del señor vicario" en el mismo claustro del convento, "frente al Santísimo Xpto. De la Buena Muerte". Su hermana Magdalena, viuda con dos hijos, recibió 500 reales de vellón (Barrio Moya, 1998, p. 354).

Según la tasación de sus bienes (realizada al casarse la primera vez por su cuñado clérigo), José Bach poseía dos libros manuscritos de órgano, uno de tocatas y otro de versos, entre otras partituras vocales e instrumentales (Barrio Moya, 1998, pp. 348, 350). Desafortunadamente, al redactar la lista de estas piezas no se incluyó el nombre de los autores (salvo en el caso de un Miserere de Diego de Las Muelas y algunas obras de José de San Juan), de ahí que no podamos determinar si existían entre ellas composiciones suyas propias.

Su desconocida obra, por tanto, podría haberse legado de padre a hijo hasta acabar en alguna colección privada o quién sabe dónde. No hay pruebas de ello, pero el José Bach que hemos encontrado entre los aspirantes a la plaza de segundo organista de la catedral de Cuenca en el año 1795 (concedida a Fernando Gil de Úbeda), bien podría ser su hijo

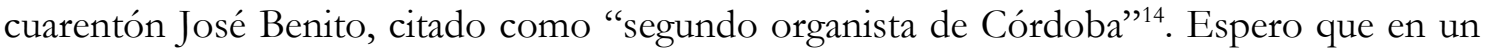
futuro no muy lejano se encuentre alguna partitura que rescate a este organista del olvido aparentemente injusto en el que ha caído.

\section{JOHANN AUGUST BACH (SIGLO XVIII)}

Este eminente abogado dejó para la posteridad varios libros de derecho civil, entre ellos uno titulado "Io. Augusti Bachii opuscula ad historiam et jurisprudentiam spectantia. Collegit et praefatus est C[hristian] A[dolph] Klotius"15.

\section{SigLO XIX}

El centro de mayor difusión de este apellido resulta ser el área de Gerona, como se puede comprobar consultando los antiguos libros de bautizos, matrimonios y defunciones de sus parroquias. En la Capilla de Los Santos Quirico y Julita, en Vergés, aparece por ejemplo un José Bach que bautiza a su hijo Vencislao Jose Emilio Bach el 19 de noviembre de 1858.

También hubo un religioso barcelonés homónimo del organista gerundense, que escribió, en 1861, una exitosa guía para el sacerdocio: "Tesoro del sacerdote o repertorio de las principales cosas que ha de saber y practicar el sacerdote para santificarse a sí mismo y santificar a los demás" (Laboa, 2000, p. 79), además de un explorador argentino en el siglo XIX y de un jugador de fútbol uruguayo, viviente.

\footnotetext{
${ }^{14}$ Es Fernando J. Cabañas Alamán que transcribe su nombre en la biografía de los organistas Francisco José Olivares y Fernando Gil de Úbeda (Real Academia de la Historia).

${ }^{15}$ Editado en 1767 (digitalizado por Google).
} 


\section{LuCa Purchiaroni}

\section{CONCLUSIONES}

Finalmente, después de descubrir a tantos Bach españoles en una cadena ininterrumpida a lo largo de casi ocho siglos, consideré que mi búsqueda no podía prescindir de la geografía y la toponimia del sitio en cuestión. El hecho de que justo en la comarca catalana de La Garrocha (provincia de Gerona) exista el Vall del Bach junto al valle de Vianya, hace suponer una presencia muy remota de poblaciones alemanas. Es muy probable que ese valle pueda haber tomado el nombre de la cercana riera, que en alemán se traduce con bach y que los catalanes llaman Oix. Lo mismo le puede haber pasado al colindante valle, por donde pasan dos rieras más (Vianya, o Bianya, cuya etimología parece ser bis amnis, que en latín significa doble río) llamadas Sant Ponç d'Aulina y Santa Llúcia de Puigmal que, juntándose, forman la riera de Vianya. De ahí el apodo, y luego apellido, con el que se empezaría a denominar a esos primeros huéspedes que hablaban una lengua tan rara para los vecinos gerundenses. Además, en Besalú, en el siglo XIV existía una parroquia del comtat de Besalú llamada St. Feliu d'es Bach y otra aún más antigua, del siglo XIII, llamada St. Jaume de Bonobach (Bolletín, 1905, II, p. 349).

Esta explicación nos sacaría de dudas acerca de la atribución de este apellido a hipotéticos cuanto remotos, antepasados del famoso Johann Sebastian, pudiendo incluso superarlos en antigüedad.

En conclusión, al final de este largo y a la vez resumido viaje en el tiempo, podemos afirmar lo siguiente: aunque me hubiera gustado encontrarlas, no hay pruebas de un enlace directo entre los Bach alemanes y españoles, a fecha de hoy. Además, el único músico español que lleva este apellido era autóctono a todos los efectos.

\section{BIBLIOGRAFÍA}

Alcover, A. M. (1905). Bolletí del diccionari de la llengua catalana, vol. 2. Mallorca: N’amengual y Muntaner.

Alcover, A. M. (2000). Documents per a la bistória de la cultura catalana medieval, vol. 2 (Reg. 968, f. 9.). Barcelona: Institut d'Estudis Catalans.

Alfonsello A. (1873). Los reys de Aragó y la Séu de Gerona desde l'any 1462 fins al 1482: Col-lecció de actes capitulares escritas per Andréu Alfonsello. Barcelona: L. Obradors y P. Sulé.

Barrio Moya, J. L. (1998). El músico gerundense Don José Bach, organista del Real Convento de Las Descalzas Reales de Madrid en el siglo XVIII. Aportaciones a su biografía, Annals de l'Istitut d'Estudis Gironins, XXXIX. pp. 343-57.

Biancolini, G. B. (1766). Notizie storiche delle chiese di Verona, vol. 7. Verona: Scolari.

Brück, H. (2008). Von der Apfelstädt und der Gera zum Missouri : 500 Jabre Thüringer Musikerfamilie Bach / Helga Brück. Jena: Glaux. 


\section{BACH: LA RAMA ESPAÑOLA}

Capdepón, P. (1997). La Capilla de música del Monasterio de las Descalzas Reales de Madrid. Anales del Instituto de Estudios Madrileños, XXXVII, pp. 215-226.

Capdepón, P. (1999). La música en el Monasterio de las Descalzas Reales (siglo XVIII). Madrid: Alpuerto.

Dalmau, R. (1971). Els Castells catalans, vol. 3. Barcelona: Rafael Dalmau.

Dameto, J.; Mut V.; Alemany, G. (1841). Historia general del reino de Mallorca. Palma de Mallorca.

Español, F. (2003). La producción seriada en calcárea numulitica de los talleres de Gerona (siglos XIII$X V)$. (Tesis doctoral). Pisa: Scuola Normale di Pisa, classe di Lettere e filosofia.

Español, F. (2009). Las manufacturas arquitectónicas en piedra de Gerona durante la baja edad media y su comercialización, Anuario de Estudios Medievales (AEM) 39(2), juliodiciembre, pp. 963-991.

Fernández, M., pbro. (2004). Parroquias madrilenas de San Martin y San Pedro el Real: algunos personajes de su Archivo. Madrid: Caparrós Editores.

Forkel, J. N. (1802), Ueber Johann Sebastian Bachs Leben, Kunst und Kunstwerke: Für patriotische Verehrer echter musikalischer Kunst. Leipzig: Hoffmeister und Kühnel.

Frickel, K. H. (1994). Genealogie der Musikerfamilia Bach. Niederwern: Eigenverlag.

Klaus-Rüdiger Mai, U. (2013). Die Bachs, eine deutsche Familie. Berlín: Ullstein eBooks.

Kock, H. (1995). Genealogisches lexikon der Familie Bach. Günthersleben-Wechmar: Gotha Druck.

Laboa, J. M. (2000). La Chiesa e la modernità, vol. 2. Milano: Jaca Book.

Ortega, J. (2010). La música en la corte de Carlos III y Carlos IV (1759-1808): de la real capilla a la real càmera. (Tesis Doctoral). Madrid: Universidad Complutense.

Subirá, J. (1957). La música en la Capilla y en el Monasterio de las Descalzas Reales de Madrid. Anuario Musical, XII, pp. 147-166.

Subirá, J. (1958). Necrologías musicales madrileñas (años 1611-1808), Anuario Musical, XIII, Barcelona.

Uda, M. (2008). Templari e Ospedalieri in Sardegna, Actas del Convenio A.R.S.O.M. del 3 de diciembre de 2006. Cagliari.

Webster, J. R. (1999). Carmel in Medieval Catalonia. Leyden-Boston-Köln: Brill. 


\section{LUCA PURCHIARONI}

\section{WEBGRAFÍA}

Family Search. Sitio de la Iglesia de los Santos de los últimos días. Recuperado de https://www.familysearch.org/.

Biblioteca Virtual Miguel de Cervantes. Recuperado de http://cervantesvirtual.com/.

Real Academia de la Historia. Recuperado de http://dbe.rah.es.

Fecha de recepción: 21/07/2020

Fecha de aceptación: 25/02/2021 